\title{
Effect of intensive prior exercise on muscle fiber activation, oxygen uptake kinetics, and oxygen uptake plateau occurrence
}

\author{
Max Niemeyer $^{1}$ D $\cdot$ Renate Leithäuser $^{1} \cdot$ Ralph Beneke $^{1}$
}

Received: 28 November 2019 / Accepted: 19 June 2020 / Published online: 27 June 2020

(c) The Author(s) 2020

\begin{abstract}
Purpose We tested the hypothesis that the described increase in oxygen uptake $\left(\dot{V} \mathrm{O}_{2}\right)$-plateau incidence following a heavysevere prior exercise is caused by a steeper increase in $\dot{V} \mathrm{O}_{2}$ and muscle fiber activation in the submaximal intensity domain. Methods Twenty-one male participants performed a standard ramp test, a $\dot{V} \mathrm{O}_{2 \max }$ verification bout, an unprimed ramp test with an individualized ramp slope and a primed ramp test with the same ramp slope, which was preceded by an intensive exercise at $50 \%$ of the difference between gas exchange threshold and maximum workload. Muscle fiber activation was recorded from vastus lateralis, vastus medialis, and gastrocnemius medialis using a surface electromyography (EMG) device in a subgroup of 11 participants. Linear regression analyses were used to calculate the $\dot{V} \mathrm{O}_{2}-\left(\Delta \dot{V} \mathrm{O}_{2} / \Delta P\right)$ and EMG$(\Delta \mathrm{RMS} / \Delta \mathrm{P})$ ramp test kinetics.

Results Twenty out of the 21 participants confirmed their $\dot{V} \mathrm{O}_{2 \max }$ in the verification bout. The $\dot{V} \mathrm{O}_{2}$-plateau incidence in these participants did not differ between the unprimed $(n=8)$ and primed $(n=7)$ ramp test $(p=0.500)$. The $\Delta \dot{V} \mathrm{O}_{2} / \Delta P$ was lower in the primed compared to the unprimed ramp test $\left(9.40 \pm 0.66\right.$ vs. $\left.10.31 \pm 0.67 \mathrm{ml} \mathrm{min}^{-1} \mathrm{~W}^{-1}, p<0.001\right)$, whereas the $\Delta \mathrm{RMS} / \Delta \mathrm{P}$ did not differ between the ramp tests $\left(0.62 \pm 0.15\right.$ vs. $\left.0.66 \pm 0.14 \% \mathrm{~W}^{-1} ; p=0.744\right)$.

Conclusion These findings do not support previous studies, which reported an increase in $\dot{V} \mathrm{O}_{2}$-plateau incidence as well as steeper increases in $\dot{V} \mathrm{O}_{2}$ and muscle fiber activation in the submaximal intensity domain following a heavy-severe prior exercise.
\end{abstract}

Keywords Cardiorespiratory fitness · Priming exercise $\cdot$ Exercise testing $\cdot$ Maximum oxygen uptake $\cdot$ Electromyography

\begin{tabular}{|c|c|}
\hline \multicolumn{2}{|c|}{ Abbreviations } \\
\hline BLC & Blood lactate concentration \\
\hline $\mathrm{BLC}_{\mathrm{BSL}}$ & $\begin{array}{l}\text { Blood lactate concentration at } 50 \mathrm{~W} \text { baseline } \\
\text { cycling }\end{array}$ \\
\hline $\mathrm{BLC}_{\max }$ & Maximal blood lactate concentration \\
\hline EMG & Electromyography \\
\hline GM & Gastrocnemius medialis \\
\hline MRT & $\begin{array}{l}\text { Mean response time of ramp test oxygen } \\
\text { uptake kinetics }\end{array}$ \\
\hline$P_{\mathrm{GET}}$ & Workload at gas exchange threshold \\
\hline$P_{\max }$ & $\begin{array}{l}\text { Maximum workload achieved at ramp test } \\
\text { termination }\end{array}$ \\
\hline
\end{tabular}

Communicated by I. Mark Olfert.

Max Niemeyer

niemeyer@staff.uni-marburg.de

1 Medizin, Training und Gesundheit, Institut für Sportwissenschaft und Motologie, Philipps-Universität Marburg, Jahnstr. 12, 35037 Marburg, Germany

\begin{tabular}{|c|c|}
\hline $\mathrm{RER}_{\max }$ & Maximal respiratory exchange ratio \\
\hline RMS & $\begin{array}{l}\text { Root mean square of the electromyography } \\
\text { signal }\end{array}$ \\
\hline $\mathrm{RMS}_{\mathrm{BSL}}$ & $\begin{array}{l}\text { Electromyography root mean square of } 50 \mathrm{~W} \\
\text { baseline cycling }\end{array}$ \\
\hline$\Delta \mathrm{RMS} / \Delta \mathrm{P}$ & $\begin{array}{l}\text { Slope of the electromyography root mean } \\
\text { square-workload-relationship }\end{array}$ \\
\hline $\mathrm{RPE}_{\max }$ & Maximal rating of perceived exertion \\
\hline $\mathrm{S}$ & Incremental rate \\
\hline S1 & $\begin{array}{l}\text { Intensity between the second minute of the } \\
\text { ramp test and } P_{\mathrm{GET}}\end{array}$ \\
\hline S2 & $\begin{array}{l}\text { Intensity between } P_{\mathrm{GET}} \text { and } 2 \text { min before } \\
\text { ramp test termination }\end{array}$ \\
\hline ST & $\begin{array}{l}\text { Intensity between the second minute of the } \\
\text { ramp test and two minutes before ramp test } \\
\text { termination }\end{array}$ \\
\hline VL & Vastus lateralis \\
\hline VM & Vastus medialis \\
\hline$\dot{V} \mathrm{CO}_{2 \max }$ & Maximal carbon dioxide production \\
\hline$\dot{\mathrm{V}} \mathrm{O}_{2}$ & Oxygen uptake \\
\hline
\end{tabular}




$\begin{array}{ll}\dot{V} \mathrm{O}_{2 \mathrm{BSL}} & \begin{array}{l}\text { Oxygen uptake of } 50 \mathrm{~W} \text { baseline cycling } \\ \dot{V} \mathrm{O}_{2 \max }\end{array} \\ \Delta \dot{V} \mathrm{O}_{2} / \Delta P & \begin{array}{l}\text { Maximal oxygen uptake } \\ \text { Slope of oxygen } \\ \text { uptake-workload-relationship }\end{array} \\ \Delta \dot{V} \mathrm{O}_{2 \max } & \begin{array}{l}\text { Slope of oxygen uptake-workload-relation- } \\ \text { ship of the final } 50 \mathrm{~W}\end{array}\end{array}$

\section{Introduction}

The oxygen uptake $\left(\dot{V} \mathrm{O}_{2}\right)$-plateau is a flattening of the linear $\dot{V} \mathrm{O}_{2}$-workload-relationship at the end of an incremental exercise test (Howley et al. 1995). It serves as an indicator of maximum oxygen uptake $\left(\dot{V} \mathrm{O}_{2 \max }\right)$, which is one of the most important measurements in exercise physiology and clinical sports medicine (Poole and Jones 2017; Hawkins et al. 2007; Levine 2008). However, even if incremental exercise has been performed with maximal effort, the observed plateau incidence is frequently less than $60 \%$ despite high levels of secondary exhaustion criteria (Lucia et al. 2006; Knaier et al. 2019b; Wood et al. 2010). It is widely believed that the occurrence of a $\dot{V} \mathrm{O}_{2}$-plateau depends on age or aerobic fitness (Howley et al. 1995; Wagner 2000; Shephard, 2009). However, there is no consistent evidence for a higher plateau incidence in young adults compared to children and older adults (Gürsel et al. 2004; Peyer et al. 2011; Edvardsen et al. 2014) or in trained compared to untrained participants (Lucia et al. 2006; Doherty et al. 2003; Day et al. 2003; Edvardsen et al. 2014; Wood et al. 2010). Instead, it has been suggested that a high anaerobic capacity increases the chance that a $\dot{V} \mathrm{O}_{2}$-plateau occurs (Gordon et al. 2011).

In a subsequent study, Gordon et al. (2012) found an increase in the plateau incidence from 50 to $100 \%$ following a prior exercise at $50 \%$ of the difference between the workload at gas exchange threshold $\left(P_{\mathrm{GET}}\right)$ and maximum workload $\left(P_{\max }\right)$. They interpreted this finding as evidence for the hypothesis that the $\dot{V} \mathrm{O}_{2}$-plateau depends on anaerobic capacity. This interpretation is based on studies that reported a slower accumulation of anaerobic metabolites following a heavy or severe priming bout (Bangsbo et al. 2001; Layec et al. 2009), suggesting a potential sparing of anaerobic capacity. Because of a rather slow time-dependent behavior of $\dot{V} \mathrm{O}_{2}$, there is a continuous accumulation of $\dot{V} \mathrm{O}_{2}$ deficit during incremental exercise tests (Niemeyer et al. 2019; Pouilly and Busso. 2008), which lead to an accumulation of anaerobic metabolites up to the individual tolerable limit (Raymer et al. 2007). Therefore, a priming-induced slower accumulation of anaerobic metabolites (i.e., a slower reduction in anaerobic capacity) should result in higher $P_{\max }$, as demonstrated by Raymer et al. 2007. Since for the diagnoses of a $\dot{V} \mathrm{O}_{2}$-plateau, $\dot{V} \mathrm{O}_{2 \max }$ must be sustained despite rather large increases in workload (Niemeyer et al. 2020), a higher
$P_{\max }$ at given $\dot{V} \mathrm{O}_{2 \max }$ should in turn increase the chance that a plateau occurs. However, Gordon et al, (2012) did not find corresponding differences in $P_{\max }$ between primed and the unprimed ramp tests. Therefore, it seems to be unlikely that the observed increase in plateau incidence is caused by an increase or sparing of anaerobic capacity. Additionally, Gordon et al. (2012) used a $\dot{V} \mathrm{O}_{2}$-plateau definition that results in a high incidence of a false plateau diagnosis (Niemeyer et al. 2020), which questions their findings considerably.

As recently demonstrated, participants with a $\dot{V} \mathrm{O}_{2}$-plateau had lower time constants of $\dot{V} \mathrm{O}_{2}$ square wave kinetics, but also steeper slopes of the $\dot{V} \mathrm{O}_{2}$-workload-relationship $\left(\Delta \dot{V} \mathrm{O}_{2} / \Delta P\right)$ in incremental ramp tests (Niemeyer et al. 2019). It is well known that the overall $\dot{V} \mathrm{O}_{2}$ response kinetics is accelerated after priming exercise bouts in the heavy or severe intensity domain (Bailey et al. 2009; Burnley et al. 2000, 2006). Since the ramp test $\dot{V} \mathrm{O}_{2}$ response is modulated by the time constant and gain of $\dot{V} \mathrm{O}_{2}$ overall kinetics, but also by the intensity-dependent increase in these parameters (Wilcox et al. 2016) in incremental ramp tests this led to an increase in $\Delta \dot{V} \mathrm{O}_{2} / \Delta P$ at workloads below and/or above $P_{\mathrm{GET}}$ (Jones and Carter 2004; Boone et al. 2012). At a given $\dot{V} \mathrm{O}_{2 \max }$, a higher $\Delta \dot{V} \mathrm{O}_{2} / \Delta P$ results in faster attainment of $\dot{V} \mathrm{O}_{2 \max }$ and therefore potentially contributes to the development of a $\dot{V} \mathrm{O}_{2}$-plateau despite a similar $P_{\max }$ (Niemeyer et al. 2019). Thus, it seems to be likely that the potential for an increase in the $\dot{V} \mathrm{O}_{2}$-plateau incidence in the primed condition is caused by an increase in $\Delta \dot{V} \mathrm{O}_{2} / \Delta P$ rather than an increase or sparing of anaerobic capacity. This alternative explanation would support the hypothesis that the $\dot{V} \mathrm{O}_{2}$ -plateau is affected by $\dot{V} \mathrm{O}_{2}$-kinetics (Niemeyer et al. 2019). However, no such analysis has previously been reported.

Boone et al. (2012) showed that the increase in $\Delta \dot{V} \mathrm{O}_{2} / \Delta P$ following priming exercise is accompanied by a steeper increase in the electromyography amplitude signal per increase in workload $(\Delta \mathrm{RMS} / \Delta \mathrm{P})$. This indicates that the prior exercise-induced increase in $\Delta \dot{V} \mathrm{O}_{2} / \Delta P$ is probably caused by elevated muscle fiber activation. Taken together therefore, we tested the hypothesis that the increase in $\dot{V} \mathrm{O}_{2}$ -plateau incidence following a prior exercise is caused by a higher $\Delta \mathrm{RMS} / \Delta \mathrm{P}$ and $\Delta \dot{V} \mathrm{O}_{2} / \Delta P$ at intensities below $\dot{V} \mathrm{O}_{2 \max }$.

\section{Methods}

We recruited 21 male students (age $25.2 \pm 2.7$ years; height $180.7 \pm 5.4 \mathrm{~cm}$; body mass $76.6 \pm 6.1 \mathrm{~kg}$ ), who were physically active but not cycling-specifically trained. The sample size was previously calculated using a power analysis for a one-tailed McNemar test. Based on the results of Gordon et al. (2012), we assumed that maximal $10 \%$ of the participants do not show a plateau in the primed ramp test and set 
the power at $90 \%$ requiring a sample size of $n=13$. To fulfill the minimum required counts per cell of the McNemar test $(n \geq 5)$, the sample size was increased to 21. All participants gave their written informed consent to participate in this study after detailed information about the potential risks of their participation. The study was approved by the ethics committee of Philipps-University Marburg, Department of Education Science (FB-21-AZ4-11-16) and conformed to the Declaration of Helsinki.

\section{Study design}

We used a randomized cross-over design to test the hypothesis. The study consisted of a series of three tests on a cycle ergometer (Cyclus-2 RBM elektronik-automation GmbH, Germany), which were separated by at least $48 \mathrm{~h}$. On the first testing day, the participants performed a standard incremental ramp test up to exhaustion with a workload increment of $30 \mathrm{~W} \mathrm{~min}{ }^{-1}$. On testing days two and three, the participants performed either an unprimed or a primed ramp test with an individualized incremental rate in randomized order, respectively. The incremental rate $(S)$ was previously calculated from the maximal workload $\left(P_{\max }\right)$ of the standard ramp test of the first testing day to allow a comparable time to exhaustion for all participants of $\sim 10 \mathrm{~min}$ (Eq. 1).

$S=\frac{P_{\max }-50}{10}$.

All ramp tests started with three minutes baseline-cycling at $50 \mathrm{~W}$. The primed ramp test was preceded by a three-step square-wave exercise with step durations of $6 \mathrm{~min}$ each. The workloads of the three steps were set at $50 \mathrm{~W}$ (step 1), $90 \%$ of the workload at the gas exchange threshold $\left(P_{\mathrm{GET}}\right)$ (step 2) and 50\% of the difference between $P_{\mathrm{GET}}$ and $P_{\text {max }}$ (step 3). Between step 3 and the ramp test, a 6-min active recovery at a workload of $50 \mathrm{~W}$ was performed. The unprimed ramp test was followed by a 12-min active recovery at $50 \mathrm{~W}$ and a subsequent $\dot{V} \mathrm{O}_{2 \max }$ verification bout. In accordance with other studies and to allow a minimum time to exhaustion of $\geq 2 \mathrm{~min}$, the workload of the verification bout was set at 90\% of $P_{\max }$ (Day et al. 2004; Sedgeman et al. 2013). The pedalling rate during the tests was set at $80 \mathrm{rpm}$, and the temperature was kept constant at $20^{\circ} \mathrm{C}$ by air condition. To avoid potential effects of diurnal variation on $\dot{V} \mathrm{O}_{2 \max }$ (Knaier et al. 2019a), all tests were performed at the same time of day $( \pm 1 \mathrm{~h})$.

\section{Measurements}

Expired air was continuously measured throughout the entire tests using a breath-by-breath device (MetaMax 3B, Cortex Biophysik GmbH, Germany). Before each test, the device was calibrated with a mixture of known gases $\left(15 \% \mathrm{O}_{2}, 5 \% \mathrm{CO}_{2}\right.$ and $80 \% \mathrm{~N}$ ) and a 3-1 syringe.

Muscle fiber activations of vastus lateralis (VL), vastus medialis (VM), and gastrocnemius medialis (GM) were measured bilateral in a subgroup of 11 participants with a surface electromyography system (TeleMyo 16-EMG DTS Noraxon USA Inc.; Scottsdale, Arizona, USA). The EMG signal was recorded at a sampling rate of $3000 \mathrm{~Hz}$ using $\mathrm{Ag} / \mathrm{AgCl}$-electrodes with a $10 \mathrm{~mm}$ diameter. The electrodes were attached to the skin at a constant inter-electrode distance of $20 \mathrm{~mm}$ and located according to the SENIAM-guidelines (Hermens et al. 1999). Previously, the skin was carefully shaved and abraded using abrasive paper and alcohol to keep the inter-electrode impedance below $2000 \Omega$. To enable the same location of electrodes in each test, the position was tagged with an indelible marker.

Blood lactate concentrations (BLC) were determined from $20-\mu$ capillary blood samples. The samples were collected from hyperaemic earlobes at rest, during the final $30 \mathrm{~s}$ of the $50 \mathrm{~W}$ baseline-cycling before the start of the ramp test, at the end of the ramp test as well as 1, 3, and 5 min after ramp test termination. Subsequently, the samples were analyzed using an enzymatic-amperometric analyzer (Biosen C-Line, EKFdiagnostic $\mathrm{GmbH}$, Germany). Maximal rating of perceived exertion $\left(\mathrm{RPE}_{\max }\right)$ was assessed at the end of the ramp test with Borg scale ranging from 6 to 20 .

\section{Data analyses and statistics}

In the first step, $\dot{V} \mathrm{O}_{2}$ was filtered by removing all values that differ more than three standard deviations from the local mean (Lamarra et al. 1987; Keier et al. 2014). $\dot{V} \mathrm{O}_{2 \max }$, maximal carbon dioxide production $\left(\dot{V} \mathrm{CO}_{2 \max }\right)$, and maximal respiratory exchange ratio $\left(\mathrm{RER}_{\max }\right)$ were calculated as the mean of the final $30 \mathrm{~s}$ of the ramp and verification test. Based on the test-retest reliability of $\dot{V} \mathrm{O}_{2 \max }$ (Katch et al. 1990; Knaier et al. 2019a), participants with a $\dot{V} \mathrm{O}_{2}$ in the verification bout more than $5 \%$ higher compared to the unprimed ramp test were excluded from the subsequent analyses. The $\dot{V} \mathrm{O}_{2}$-plateau was determined from the slope of the $\dot{V} \mathrm{O}_{2}$-workloadrelationship of the final $50 \mathrm{~W}\left(\Delta \dot{V} \mathrm{O}_{2 \max }\right)$ using linear regression analyses. Based on previous recommendations (Niemeyer et al. 2020), a plateau was accepted if the slope was less than $5.0 \mathrm{ml} \mathrm{min}{ }^{-1} \mathrm{~W}^{-1}$, which represents approximately half of the expected slope in the submaximal intensity domain (Boone and Bourgois 2012).

Linear regression analyses were also used to calculate the $\Delta \dot{V} \mathrm{O}_{2} / \Delta P$ (Eq. 2), where the slope (m) of the $\dot{V} \mathrm{O}_{2}$-workload-relationship represents the $\Delta \dot{V} \mathrm{O}_{2} / \Delta P$. Furthermore, $P$ is defined as the workload, and $\mathrm{b}$ as the intercept.

$\dot{V} O_{2}=m \cdot P+b$. 
In accordance with Jones and Carter (2004), we calculated the $\Delta \dot{V} \mathrm{O}_{2} / \Delta P$ in three submaximal intensity domains: from one minute into the ramp test up to $P_{\mathrm{GET}}(\mathrm{S} 1)$, from $P_{\mathrm{GET}}$ up to two minutes before ramp test termination (S2), and from one minute into the ramp test up to 2 min before ramp test termination (ST). $P_{\mathrm{GET}}$ was previously determined using the $V$-slope method (Beaver et al. 1986). The mean response time of the $\dot{V} \mathrm{O}_{2}$ ramp test response (MRT) was calculated from the interception point of the $\dot{V} \mathrm{O}_{2}$-workloadrelationship below $P_{\mathrm{GET}}(\mathrm{S} 1)$ and a horizontal line crossing the $\dot{V} \mathrm{O}_{2}$ of $50 \mathrm{~W}$ baseline-cycling, which precedes the ramp test (Eq. 3):

$\mathrm{MRT}=\frac{\dot{V} O_{2 \mathrm{BSL}}-b \_S 1}{\Delta \dot{V} O_{2} / \Delta P \_S 1 \cdot S}-\frac{50}{S}$,

where $\dot{V} \mathrm{O}_{2 \mathrm{BSL}}$ was previously calculated as the mean $\dot{V} \mathrm{O}_{2}$ of the last $60 \mathrm{~s}$ of the $50 \mathrm{~W}$ baseline cycling and $S$ was the ramp slope with the unit $\mathrm{W} \mathrm{s}^{-1} . \Delta \dot{V} \mathrm{O}_{2} / \Delta P \_S 1$ and $b \_S 1$ were defined as slope and the intercept of the $\dot{V} \mathrm{O}_{2}$-workloadrelationship below $P_{\mathrm{GET}}(\mathrm{S} 1)$.

The raw EMG signal was bandpass filtered between 10 and $500 \mathrm{~Hz}$, rectified and smoothed using a moving root mean square (RMS) of $100 \mathrm{~ms}$. Subsequently, the RMS was averaged over $10 \mathrm{~s}$ intervals and time-aligned to the beginning of the ramp test. Then, we averaged the RMS of both legs separately for every muscle (VL; VM and GM) as well as for all muscles together (all). Finally, the ramp test RMS was normalized to the mean RMS of the last minute of the $50 \mathrm{~W}$-baseline cycling, which precedes the ramp tests (Mirka 1991; Boone et al. 2012). The RMS-workload relationship was quantified by calculating the $\Delta \mathrm{RMS} / \Delta \mathrm{P}$ over the same workload ranges as previously performed for the $\Delta \dot{V} \mathrm{O}_{2} / \Delta P$ using linear regression analyses.

Descriptive data are presented as mean $\pm \mathrm{SD}$. We compared the plateau incidences in the unprimed and primed ramp tests using a one-tailed McNemar test and calculated the effect size Cohen's $g$. All other maximal exercise data of both ramp tests were compared with $t$ tests for paired samples and the corresponding effect size Cohen's d. Analyses of variance were used to compare the $\Delta \dot{V} \mathrm{O}_{2} / \Delta P$ and $\Delta \mathrm{RMS} / \Delta \mathrm{P}$ between the conditions. For this purpose, the separate intensity regions of the $\dot{V} \mathrm{O}_{2}$ and RMS-workload slopes ( $S 1, S 2$ and $\mathrm{ST}$ ) and the prior exercise (unprimed vs. primed) were defined as two independent within-subject factors. $\eta^{2}$ was calculated as the corresponding effect size. Post hoc comparisons were performed using $t$ tests for paired samples and Bonferroni adjustments. To represent the mean $\dot{V} \mathrm{O}_{2}$ and RMS responses in Figs. 1 and 2, we calculated the mean values in $10 \mathrm{~s}$ intervals and averaged the values of all participants. To enable a similar number of cases despite varying times to exhaustion, we averaged the $10 \mathrm{~s}$ intervals up to the average time to exhaustion minus $2 \mathrm{~min}$ (submaximal intensity domain) as well as the final 2 min of every single participant (maximal intensity domain).

\section{Results}

One participant showed a more than $5 \%$ higher $\dot{V} \mathrm{O}_{2 \max }$ in the verification test compared with the unprimed ramp test and was excluded from the subsequent analyses. As shown in Table 1 , the plateau incidence $(p=0.500 ; g=0.00)$ as well as the corresponding $\Delta \dot{V} \mathrm{O}_{2 \max }(p=0.962 ; d=0.01)$ did not differ between the unprimed and primed ramp tests. Five out of the eight participants that had a plateau in the unprimed ramp test showed a plateau in the primed ramp test also. Three participants had a plateau in the unprimed but not in the primed ramp test. Two participants showed no plateau in the unprimed but in the primed ramp test. $\dot{V} \mathrm{O}_{2 \max }(p=0.032 ; d=0.52), \dot{V} \mathrm{CO}_{2 \max }(p<0.001 ; d=1.65)$, $P_{\text {max }}(p=0.001 ; d=0.86), \operatorname{RER}_{\text {max }}(p<0.001 ; d=1.30)$ and $\mathrm{BLC}_{\text {max }}(p=0.006 ; d=0.69)$ were significantly lower in the primed ramp test. Only $\operatorname{BLC}_{\mathrm{BSL}}(p<0.001 ; d=2.48)$ and $\operatorname{RPE}_{\text {max }}(p=0.014 ; d=0.60)$ were higher in the primed than in the unprimed ramp test.

\section{$\dot{V} \mathrm{O}_{2}$-kinetics}

The $\dot{V} \mathrm{O}_{2}$-kinetics of the unprimed and primed ramp tests is displayed in Fig. 1 and Table 2. The $\dot{V} \mathrm{O}_{2}$ at the end of the $50 \mathrm{~W}$ baseline cycling was significantly higher before the primed than in the unprimed ramp test $(p<0.001 ; d=1.73)$. No significant difference between the conditions was evident

Table 1 Maximal and submaximal exercise data of the unprimed and primed ramp test $(n=20)$

\begin{tabular}{|c|c|c|}
\hline & Unprimed & Primed \\
\hline Plateau incidence $(n(\%))$ & $8(40 \%)$ & $7(35 \%)$ \\
\hline$\Delta \dot{V} \mathrm{O}_{2 \max }\left(\mathrm{ml} \cdot \mathrm{min}^{-1} \cdot \mathrm{W}^{-1}\right)$ & $6.90 \pm 4.30$ & $6.84 \pm 5.07$ \\
\hline$\dot{V} \mathrm{O}_{2 \max }\left(1 \cdot \min ^{-1}\right)$ & $4.12 \pm 0.49$ & $3.97 \pm 0.52 *$ \\
\hline$\dot{V} \mathrm{CO}_{2 \max }\left(1 \cdot \min ^{-1}\right)$ & $5.14 \pm 0.64$ & $4.61 \pm 0.71 *$ \\
\hline$P_{\max }(\mathrm{W})$ & $371.0 \pm 51.4$ & $358.2 \pm 56.6^{*}$ \\
\hline $\mathrm{RER}_{\max }$ & $1.25 \pm 0.05$ & $1.16 \pm 0.06^{*}$ \\
\hline $\mathrm{BLC}_{\max }\left(\mathrm{mmol} \cdot 1^{-1}\right)$ & $14.57 \pm 1.70$ & $13.27 \pm 1.36^{*}$ \\
\hline $\mathrm{BLC}_{\mathrm{BSL}}\left(\mathrm{mmol} \mathrm{1}^{-1}\right)$ & $1.00 \pm 0.22$ & $7.63 \pm 2.67 *$ \\
\hline $\mathrm{RPE}_{\max }$ & $18.6 \pm 1.4$ & $19.2 \pm 1.3^{*}$ \\
\hline
\end{tabular}

Data are Mean \pm SD

$\Delta \dot{V} O_{2 \max }$ increase in $\dot{V} \mathrm{O}_{2}$ within the last $50 \mathrm{~W}, \dot{V} O_{2 \max }$ maximum oxygen uptake, $\dot{V} C O_{2 \max }$ maximum carbon dioxide production, $P_{\max }$ maximum workload, $R E R_{\max }$ maximal respiratory exchange ratio, $B L C_{\max }$ maximal blood lactate concentration, $B L C_{B S L}$ blood lactate concentration at $50 \mathrm{~W}$-baseline cycling before the corresponding ramp tests, $R P E_{\text {max }}$ maximal rating of perceived exertion

*Significantly different from the unprimed ramp test 
Fig. 1 Mean group $(n=20)$ $\dot{V} \mathrm{O}_{2}$-kinetics of the unprimed (closed circle) and primed (open circle) ramp test; a up to $120 \mathrm{~s}$ before ramp test termination; $\mathbf{b}$ during the final $120 \mathrm{~s}$

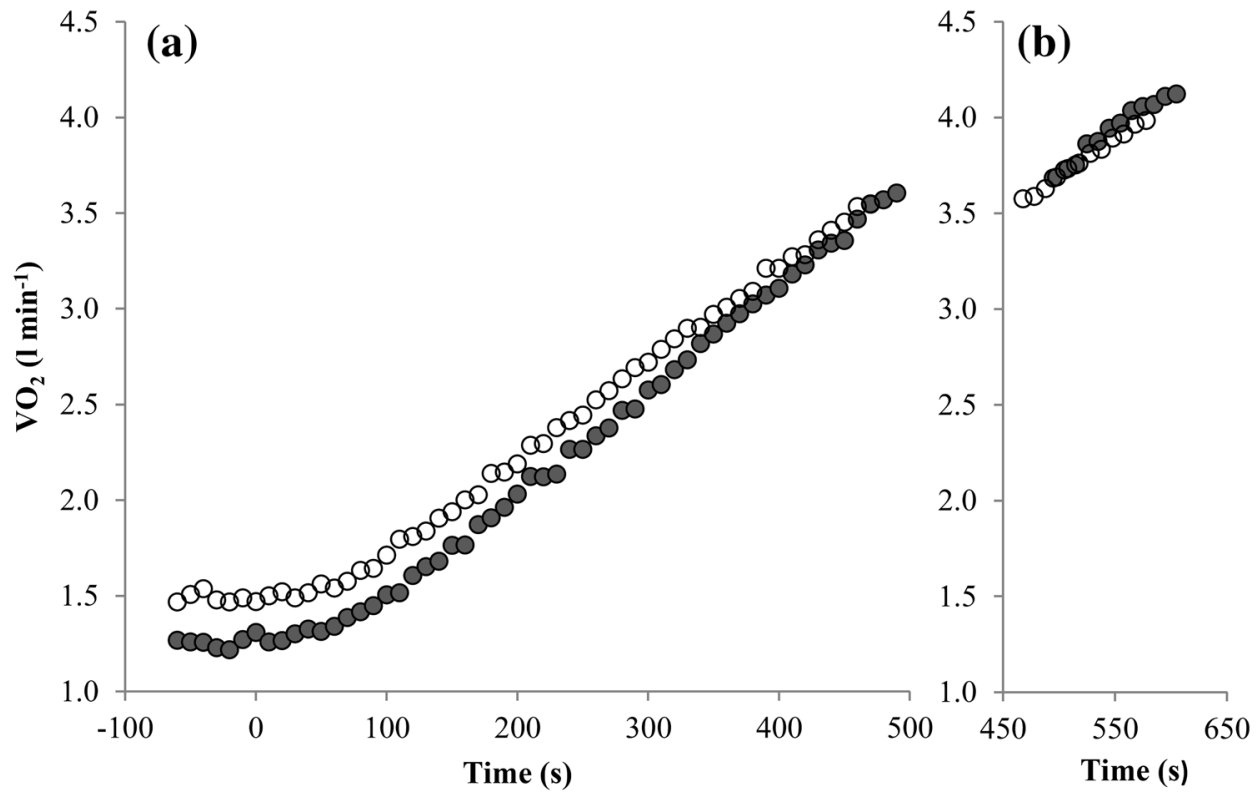

Table $2 \dot{V} \mathrm{O}_{2}$-kinetics of the unprimed and primed ramp test $(n=20)$

\begin{tabular}{lcc}
\hline & Unprimed & Primed \\
\hline$\dot{V} \mathrm{O}_{2 \mathrm{BSL}}\left(1 \cdot \mathrm{min}^{-1}\right)$ & $1.26 \pm 0.10$ & $1.49 \pm 0.16^{*}$ \\
$\mathrm{MRT}(\mathrm{s})$ & $45.5 \pm 13.0$ & $46.1 \pm 20.0$ \\
$\Delta \dot{V} \mathrm{O}_{2} / \Delta P \_\mathrm{S} 1\left(\mathrm{ml} \cdot \mathrm{min}^{-1} \mathrm{~W}^{-1}\right)$ & $9.56 \pm 0.89$ & $9.36 \pm 2.28$ \\
$\Delta \dot{V} \mathrm{O}_{2} / \Delta P \_\mathrm{S} 2\left(\mathrm{ml} \cdot \mathrm{min}^{-1} \mathrm{~W}^{-1}\right)$ & $10.41 \pm 0.69$ & $9.21 \pm 0.79^{*}$ \\
$\Delta \dot{V} \mathrm{O}_{2} / \Delta P \_\mathrm{ST}\left(\mathrm{ml} \cdot \mathrm{min}^{-1} \mathrm{~W}^{-1}\right)$ & $10.31 \pm 0.67$ & $9.40 \pm 0.66^{*}$ \\
\hline
\end{tabular}

Data are Mean \pm SD

$\dot{V} O_{2 B S L}$ oxygen uptake at $50 \mathrm{~W}$-baseline cycling before the corresponding ramp tests, $M R T$ mean response time of ramp test $\dot{V} \mathrm{O}_{2}$ -kinetics, $\Delta \dot{V} O_{2} / \Delta P$ slope of the linear oxygen uptake-workloadrelationship, $S 1$ intensity between the second minute of ramp test and $P_{\mathrm{GET}}, S 2$ intensity between $P_{\mathrm{GET}}$ and 2 min before ramp test termination, $S T$ intensity between the second minute of ramp test and 2 min before ramp test termination

*Significantly different from the unprimed ramp test

with respect to the MRT ( $p=0.902 ; d=0.03$ ). The ANOVA revealed no effect of the exercise intensity domain on the $\Delta \dot{V} \mathrm{O}_{2} / \Delta P\left(F(1.09,20.79)=1.600 ; p=0.222 ; \eta^{2}=0.08\right)$, which indicates that $\Delta \dot{V} \mathrm{O}_{2} / \Delta P$ did not differ over the three distinct intensity regions (S1, S2 and ST) In contrast, the $\Delta \dot{V} \mathrm{O}_{2} / \Delta P$ was significantly affected by the prior exercise $\left(F(1,19)=21.66 ; p<0.001 ; \eta^{2}=0.53\right)$. Subsequent pairwise comparisons revealed significantly lower $\Delta \dot{V} \mathrm{O}_{2} / \Delta P$ in the primed ramp test in the $\mathrm{S} 2(p<0.001 ; d=1.24)$ and $\mathrm{ST}(p<0.001 ; d=1.48)$ intensity domains.

\section{EMG-kinetics}

Figure 2 and Table 3 show the EMG-kinetics of the unprimed and primed ramp tests. $\mathrm{RMS}_{\mathrm{BSL}}$ of the three recorded muscles appeared to be unaffected by the prior exercise (VL: $p=0.052 ; d=0.66$; VM: $p=0.280 ; d=0.34$; GM: $p=0.317 ; d=0.32$; all: $p=0.243 ; d=0.37)$. Also, $\Delta \mathrm{RMS} / \Delta \mathrm{P}$ of the three recorded muscles did not differ between the primed and unprimed ramp tests (VL: $F(1.00,10.00)=3.796 ; p=0.080 ; \eta^{2}=0.28 ; \mathrm{VM}$ : $F(1.00,10.00)=0.101 ; p=0.758 ; \eta^{2}=0.01 ; \mathrm{GM}: F$ $(1.00,10.00)=1.421 ; p=0.261 ; \eta^{2}=0.12 ;$ all: $F(1.00$, $\left.10.00)=0.113 ; p=0.744 ; \eta^{2}=0.01\right)$. Furthermore, $\Delta \mathrm{RMS} / \Delta \mathrm{P}$ did not differ over the three exercise intensity domains (VL: $F(1.05,10.52)=1.604 ; p=0.234 ; \eta^{2}=0.14$; VM: $F(1.11,11.14)=0.179 ; p=0.707 ; \eta^{2}=0.02 ; \mathrm{GM}: F$ $(1.29,12.86)=1.161 ; p=0.318 ; \eta^{2}=0.10 ;$ all: $F(1.09$, $\left.10.87)=0.220 ; p=0.668 ; \eta^{2}=0.02\right)$ and there were no interaction effects between the exercise intensity domains and the prior exercise (VL: $F(1.07,10.67)=1.561$; $p=0.240 ; \eta^{2}=0.14 ; \mathrm{VM}: F(1.08,10.80)=0.392$; $p=0.560 ; \eta^{2}=0.04 ; \mathrm{GM}: F(1.02 ; 10.17)=1.013$; $p=0.339 ; \eta^{2}=0.09 ;$ all: $F(1.09,10.89)=1.766 ; p=0.213$; $\left.\eta^{2}=0.15\right)$.

\section{Discussion}

The main finding of our study is that a heavy-severe prior exercise did not change the $\dot{V} \mathrm{O}_{2}$-plateau incidence. Furthermore, we did not find an increase in $\Delta \mathrm{RMS} / \Delta \mathrm{P}$ and even a reduction in $\Delta \dot{V} \mathrm{O}_{2} / \Delta P$ in the $\mathrm{S} 2$ and $\mathrm{ST}$ intensity domains. The outcomes of our study are therefore contrary to our hypothesis as well as previous findings (Jones and Carter 2004; Boone et al. 2012; Gordon et al. 2012). 
Fig. 2 Mean subgroup $(n=11)$ EMG-kinetics (average of all muscles) of the unprimed (closed circle) and primed (open circle) ramp test; $\mathbf{a}$ up to $120 \mathrm{~s}$ before ramp test termination; $\mathbf{b}$ during the final $120 \mathrm{~s}$

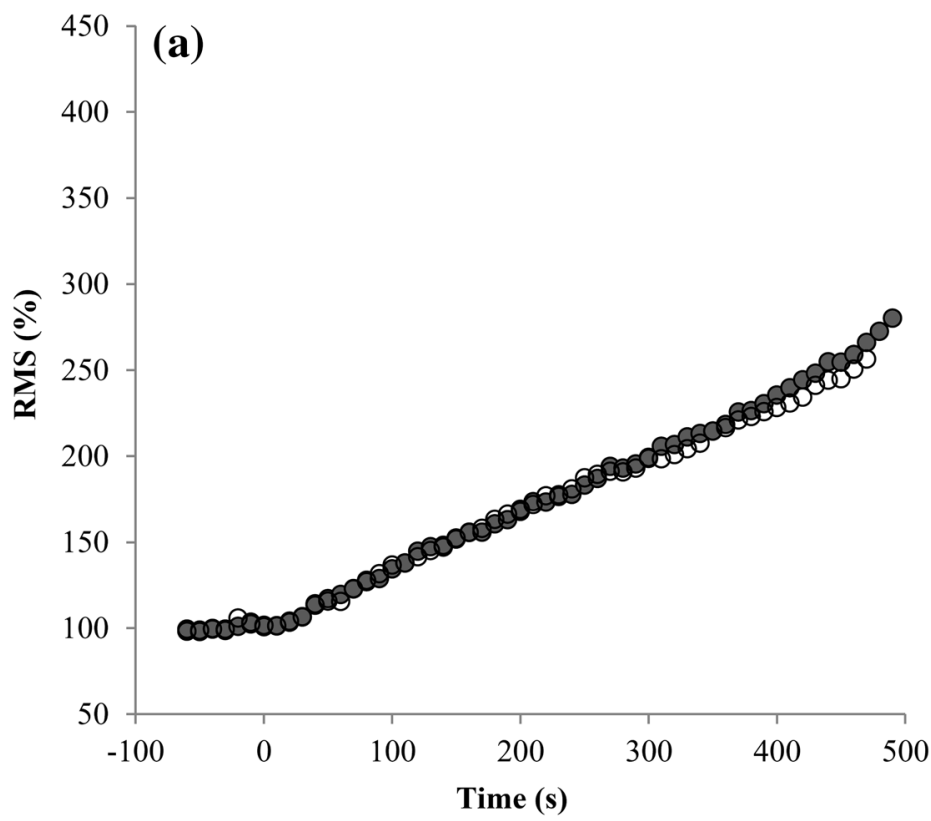

Table 3 EMG-kinetics of the unprimed and primed ramp test $(n=11)$

\begin{tabular}{|c|c|c|c|}
\hline Muscle & Measurement & Unprimed & Primed \\
\hline \multirow[t]{4}{*}{ Vastus lateralis } & $\mathrm{RMS}_{\mathrm{BSL}}(\mu \mathrm{V})$ & $32.4 \pm 8.2$ & $34.8 \pm 9.5$ \\
\hline & $\Delta \mathrm{RMS} / \Delta P \_S 1\left(\% \mathrm{~W}^{-1}\right)$ & $0.94 \pm 0.33$ & $0.93 \pm 0.33$ \\
\hline & $\Delta \mathrm{RMS} / \Delta P \_S 2\left(\% \mathrm{~W}^{-1}\right)$ & $1.15 \pm 0.41$ & $0.97 \pm 0.37$ \\
\hline & $\Delta \mathrm{RMS} / \Delta \mathrm{P} \_\mathrm{ST}\left(\% \mathrm{~W}^{-1}\right)$ & $1.08 \pm 0.34$ & $0.94 \pm 0.28$ \\
\hline \multirow[t]{4}{*}{ Vastus medialis } & $\operatorname{RMS}_{\mathrm{BSL}}(\mu \mathrm{V})$ & $50.2 \pm 14.0$ & $53.0 \pm 15.6$ \\
\hline & $\Delta \mathrm{RMS} / \Delta P \_S 1\left(\% \mathrm{~W}^{-1}\right)$ & $1.13 \pm 0.51$ & $1.18 \pm 0.46$ \\
\hline & $\Delta \mathrm{RMS} / \Delta P \_S 2\left(\% \mathrm{~W}^{-1}\right)$ & $1.14 \pm 0.40$ & $1.06 \pm 0.45$ \\
\hline & $\Delta \mathrm{RMS} / \Delta \mathrm{P} \_\mathrm{ST}\left(\% \mathrm{~W}^{-1}\right)$ & $1.15 \pm 0.35$ & $1.09 \pm 0.41$ \\
\hline \multirow[t]{4}{*}{ Gastrocnemius medialis } & $\operatorname{RMS}_{\mathrm{BSL}}(\mu \mathrm{V})$ & $74.5 \pm 25.4$ & $78.7 \pm 22.6$ \\
\hline & $\Delta \mathrm{RMS} / \Delta P \_S 1\left(\% \mathrm{~W}^{-1}\right)$ & $0.16 \pm 0.13$ & $0.19 \pm 0.19$ \\
\hline & $\Delta \mathrm{RMS} / \Delta P \_S 2\left(\% \mathrm{~W}^{-1}\right)$ & $0.26 \pm 0.19$ & $0.19 \pm 0.15$ \\
\hline & $\Delta \mathrm{RMS} / \Delta \mathrm{P} \_\mathrm{ST}\left(\% \mathrm{~W}^{-1}\right)$ & $0.21 \pm 0.14$ & $0.18 \pm 0.12$ \\
\hline \multirow[t]{4}{*}{ All muscles } & $\operatorname{RMS}_{\mathrm{BSL}}(\mu \mathrm{V})$ & $52.4 \pm 10.6$ & $54.6 \pm 14.5$ \\
\hline & $\Delta \mathrm{RMS} / \Delta P \_S 1\left(\% \mathrm{~W}^{-1}\right)$ & $0.61 \pm 0.20$ & $0.66 \pm 0.16$ \\
\hline & $\Delta \mathrm{RMS} / \Delta P \_S 2\left(\% \mathrm{~W}^{-1}\right)$ & $0.69 \pm 0.22$ & $0.63 \pm 0.20$ \\
\hline & $\Delta \mathrm{RMS} / \Delta \mathrm{P} \_\mathrm{ST}\left(\% \mathrm{~W}^{-1}\right)$ & $0.66 \pm 0.14$ & $0.62 \pm 0.15$ \\
\hline
\end{tabular}

Data are Mean \pm SD

$R M S_{B S L}$ root mean square of the EMG-signal at the final minute of $50 \mathrm{~W}$-baseline cycling before the corresponding ramp tests, $\triangle R M S / \Delta P$ slope of the root mean square-workload-relationship, $S 1$ intensity between the second minute of ramp test and $P_{\mathrm{GET}}, S 2$ intensity between $P_{\mathrm{GET}}$ and 2 min before ramp test termination, $S T$ intensity between the second minute of ramp test and 2 min before ramp test termination

\section{Effect of prior exercise on the $\mathrm{VO}_{2}$-plateau incidence}

Gordon et al. (2012) described in a group of 12 cyclists a significant increase in the plateau incidence from 50 to $100 \%$ after a prior exercise at $50 \%$ of the difference between $P_{\mathrm{GET}}$ and $P_{\max }$. Furthermore, they found a trend towards an increase from 50 to $82 \%$ after a prior exercise at
$80 \%$ of the difference between $P_{\mathrm{GET}}$ and $P_{\max }$. Although we used a comparable prior exercise, which also comprised a 6-min exercise bout at 50\% of the difference between $P_{\mathrm{GET}}$ and $P_{\max }$ as well as a subsequent 6-min active recovery, the plateau incidence was mostly unaffected in our study.

In addition to this outcome, we also found a significant reduction in $\dot{V} \mathrm{O}_{2 \max }$ and $P_{\max }$ in the primed compared with the unprimed ramp test. According to previous prior exercise 
studies, this indicates that the recovery between the prior exercise and the subsequent ramp test was too short, which results in an impaired anaerobic capacity and a reduced exercise tolerance (Ferguson et al. 2007; Bailey et al. 2009; Wittekind et al. 2012). Since the occurrence of a $\dot{V} \mathrm{O}_{2}$-plateau has been related to anaerobic capacity (Gordon et al. 2011), the absence of an increase in the plateau incidence may be caused by a too fatiguing prior exercise or insufficient recovery. However, even in the participants with a mostly similar $P_{\max }( \pm 10 \mathrm{~W})$ in the unprimed and primed ramp test $(n=9)$ we did not find an increase in the plateau incidence $(n=5$ and 4 in the unprimed and primed ramp test, respectively). Therefore, an insufficient recovery of anaerobic capacity and the resulting reduction in $P_{\max }$ may not be the sole cause for the absence of an increase in the plateau incidence.

Another potential reason for the divergent findings may be the procedure of $\dot{V} \mathrm{O}_{2}$-plateau determination. We accepted a plateau when the $\Delta \dot{V} \mathrm{O}_{2} / \Delta P$ of the final $50 \mathrm{~W}$ was less than $5.0 \mathrm{ml} \mathrm{min}^{-1} \mathrm{~W}^{-1}$. As recently shown (Niemeyer et al. 2020), this definition enables to detect a plateau with a risk of false plateau diagnoses below 5\%. Gordon et al. (2012) determined the $\dot{V} \mathrm{O}_{2}$-plateau from the difference between the last and next-to-last $30 \mathrm{~s}$ of a ramp test with an incremental rate of $30 \mathrm{~W} \mathrm{~min}{ }^{-1}$. They accepted a plateau when the difference was less than $2.1 \mathrm{ml} \mathrm{min}^{-1} \mathrm{~kg}^{-1}$. Since the mean workload of two consecutive $30 \mathrm{~s}$ intervals differs by about $15 \mathrm{~W}$, the expected mean increase in $\dot{V} \mathrm{O}_{2}$ in the submaximal intensity domain is $\sim 150 \mathrm{ml} \mathrm{min}^{-1}$ (assuming a $\Delta \dot{V} \mathrm{O}_{2} / \Delta P$ of $10 \mathrm{ml} \mathrm{min}^{-1} \mathrm{~W}^{-1}$ ). Because the average body mass in the study by Gordon et al. (2012) was $69 \mathrm{~kg}$, their mean cut-off was in fact set at $145 \mathrm{ml} \mathrm{min}{ }^{-1}$, which is only $5 \mathrm{ml} \mathrm{min}{ }^{-1}$ below the expected increase in $\dot{V} \mathrm{O}_{2}$, if no plateau occurs. If the plateau definition of Gordon et al. (2012) is applied to our data, the plateau incidence in the unprimed and primed ramp tests increases to 80 and $65 \%$, respectively. It is therefore very likely that the findings of Gordon et al. (2012) are affected by a high frequency of false-positive plateau diagnoses (Niemeyer et al. 2020).

\section{Effect of prior exercise on $\Delta \dot{V} O_{2} / \Delta P$}

Contrary to our hypothesis, we found a comparable $\Delta \dot{V} \mathrm{O}_{2} / \Delta P$ in the $S 1$ and even a reduction in the $S 2$ and ST intensity domains, as shown in Fig. 1 and Table 2. Previously, an increase in $\Delta \dot{V} \mathrm{O}_{2} / \Delta P$ after a prior exercise has been described. However, the findings are inconsistent. Jones and Carter (2004) described an increase in the $S 2$ and ST intensity domains, whereas Boone et al. (2012) found an increase in the $S 1$ and a reduction in the $S 2$ domain. Marles et al. (2006) and Ferguson et al. (2007) did not find any change of $\Delta \dot{V} \mathrm{O}_{2} / \Delta P$ after an intensive prior exercise.

These contradictory findings are potentially caused by methodological differences in terms of the protocol of the prior exercise and the subsequent recovery. The aim of the present study was to test whether the described increase in the $\dot{V} \mathrm{O}_{2}$-plateau incidence after an intensive prior exercise (Gordon et al. 2012) is caused by a higher $\Delta \dot{V} \mathrm{O}_{2} / \Delta P$, which results in faster attainment of $\dot{V} \mathrm{O}_{2 \max }$ and therefore contributes to the development of a $\dot{V} \mathrm{O}_{2}$-plateau despite a similar $P_{\text {max }}$. Thus, we chose a very similar experimental design as described by Gordon et al. (2012). In contrast to our study and the study of Gordon et al. (2012), Jones \& Carter (2004), as well as Boone et al. (2012) used incremental ramp tests as prior exercises. Since these ramp tests were performed up to exhaustion, it is likely that the priming interventions were more intensive than in our and the Gordon et al (2012) study. However, the $\mathrm{BLC}_{\mathrm{BSL}}$ immediately before the start of the primed ramp test in our study was very similar compared to the corresponding values reported by Jones and Carter (2004) and Boone et al. (2012). Furthermore, it has been shown that even a priming exercise in the heavy intensity domain, which goes along with much lower BLC values, led to speeding of $\dot{V} \mathrm{O}_{2}$ kinetics (Burnley et al. 2000, 2006). Consequently, it seems to be rather unlikely that the intensity of the prior exercise was too low to induce a speeding of $\dot{V} \mathrm{O}_{2}$ overall kinetics and a corresponding increase in $\Delta \dot{V} \mathrm{O}_{2} / \Delta P$.

In accordance with the study of Gordon et al. (2012), we chose a 6-min active recovery between the prior exercise bout and the primed ramp test. Thus, the recovery protocol of our study was slightly different from the studies of Jones and Carter (2004) and Boone et al. (2012), which used a 10-min active recovery (Jones and Carter 2004) or a 3-min rest followed by a 3-min active recovery (Boone et al. 2012). It seems to be possible that the duration or kind of recovery (rest vs. low-intensity cycling) affects the $\dot{V} \mathrm{O}_{2}$-ramp test kinetics.

As shown in Table 2 and Fig. 1, $\dot{V} \mathrm{O}_{2}$ at baseline-cycling preceding the ramp tests was significantly elevated in the primed condition. A potential explanation for this may be an increased activation of less efficient type 2 muscles fibers (Han et al. 2003). However, this explanation is rather unlikely because the EMG signal did not differ between the primed and the unprimed ramp test. Instead, it seems to be likely that the elevated $\dot{V} \mathrm{O}_{2}$ at baseline-cycling and the beginning of the ramp test results from an elevated $\dot{V} \mathrm{O}_{2}$ demand, which is caused by the same mechanisms that are responsible for the excess post-exercise oxygen consumption (EPOC) (Børsheim and Bahr 2003). The EPOC leads to an increase in $\dot{V} \mathrm{O}_{2}$ not only at rest but also at subsequent low-intensity exercise (Bangsbo et al. 1994; Børsheim and Bahr 2003). The EPOC decreases exponentially with time (Børsheim and Bahr 2003). Therefore, with respect to the rather short recovery duration used in our study, it is possible that a potential increase in $\Delta \dot{V} \mathrm{O}_{2} / \Delta P$ in the $S 1$ and ST domain is superimposed by the EPOC kinetics. Furthermore, the reduction in EPOC with time is much more pronounced 
during rest compared to active recovery, as described by Bangsbo et al. (1994). This may explain why Boone et al. (2012) found an increase in $\Delta \dot{V} \mathrm{O}_{2} / \Delta P$ in the $S 1$ domain, despite using a recovery duration of $6 \mathrm{~min}$ also. Therefore, a passive and/or longer recovery phase may be more suitable to induce an increase in $\Delta \dot{V} \mathrm{O}_{2} / \Delta P$. However, the effect of the recovery mode or duration on the change of ramp tests kinetics after a priming exercise has never been examined.

At the first glance, the priming-induced reduction in $\Delta \dot{V} \mathrm{O}_{2} / \Delta P$ in the $S 2$ intensity domain seems to be caused by a reduced slow component of $\dot{V} \mathrm{O}_{2}$-kinetics. Especially in ramp tests with low incremental rates $\left(<30 \mathrm{~W} \mathrm{~min}^{-1}\right)$, a slightly upward deflection of the $\dot{V} \mathrm{O}_{2}$-workload-relationship has been reported at workloads above $P_{\mathrm{GET}}$ (Boone and Bourgois 2012). This upward deflection has been related to the same mechanisms that are responsible for the slow component of $\dot{V} \mathrm{O}_{2}$-kinetics (Grassi et al. 2015). It is well known that a priming exercise in the heavy or severe intensity domain reduces the magnitude of the slow component (Bailey et al. 2009; Burnley et al. 2000; 2006). However, this reduction is not based on a lower $\dot{V} \mathrm{O}_{2}$ at the end of a constant load bout, which would indicate a lower gain of overall $\dot{V} \mathrm{O}_{2}$-kinetics (i.e., a higher delta-efficiency). Instead, the reduction in the slow component is caused by a higher amplitude of the primary/fast component of $\dot{V} \mathrm{O}_{2}$-kinetics (Bailey et al. 2009; Burnley et al. 2000, 2006). Thus, an increase in the fast component amplitude and a resulting speeding of $\dot{V} \mathrm{O}_{2}$ overall kinetics should lead to an increase in $\Delta \dot{V} \mathrm{O}_{2} / \Delta P$ in the $S 2$ and ST intensity domains (Wilcox et al. 2016), as demonstrated by Jones and Carter (2004). Reasons for our contrary findings are unclear and must be examined in subsequent studies.

\section{Effect of prior exercise on $\Delta R M S / \Delta P$}

In the study of Boone et al. (2012), the increase in $\Delta \dot{V} \mathrm{O}_{2} / \Delta P$ in the $\mathrm{S} 1$ intensity domain was accompanied by a steeper increase in the integrated EMG-signal of the left vastus lateralis. This indicates that the higher $\Delta \dot{V} \mathrm{O}_{2} / \Delta P$ is caused by elevated muscle fiber activation. Despite recording the EMG-signal from VL, VM and GM of each leg, we did not find any changes in $\Delta \mathrm{RMS} / \Delta \mathrm{P}$. Since we also did not find an increase in $\Delta \dot{V} \mathrm{O}_{2} / \Delta P$ in the $S 1$ intensity domain, the similar $\Delta \mathrm{RMS} / \Delta \mathrm{P}$ in the unprimed and primed ramp test does not challenge the finding that the priming-induced increase in $\Delta \dot{V} \mathrm{O}_{2} / \Delta P$ is caused by elevated muscle fiber recruitment (Boone et al. 2012).

The reasons for these different findings are unclear. Unlike our study, Boone et al. (2012) used a ramp exercise bout as a priming intervention. This approach enables to measure muscle fiber activation of the primed and unprimed ramp test within the same electrode application. However, we tagged the position of the electrodes with an indelible marker to ensure the same position despite the ramp tests being performed on different days. Furthermore, the RMS signal was normalized to the mean RMS of the last minute of the $50 \mathrm{~W}$-baseline cycling. Therefore, it is unlikely that the divergent findings are caused by changes in the electrode applications.

As described above, the recovery protocol of our study was slightly different compared to the study of Boone et al. (2012). Therefore, it cannot be excluded that the absence of an increase in $\Delta \mathrm{RMS} / \Delta \mathrm{P}$ in our study is caused by the use of a 6-min active recovery instead of a 3-min rest followed by a 3 -min baseline-cycling at $50 \mathrm{~W}$, as performed by Boone et al. (2012).

\section{Conclusions}

Contrary to our hypotheses and previous studies, we were not able to demonstrate an increase in plateau incidence, $\Delta \dot{V} \mathrm{O}_{2} / \Delta P$ and $\Delta \mathrm{RMS} / \Delta \mathrm{P}$ following an intensive prior exercise. This is potentially caused by differences in the priming exercise or the recovery period between the warm-up and the ramp test, which has to be checked in subsequent studies.

Acknowledgements Open Access funding provided by Projekt DEAL. We thank all persons who made this study possible by their participation

Author contributions MN conceived and designed research, conducted experiments, analyzed data and wrote the manuscript. RL and $\mathrm{RB}$ wrote and critically revised the manuscript. All authors read and approved the manuscript.

Funding No funding was received for this study.

\section{Compliance with ethical standards}

Conflict of interest The authors declare that they have no conflict of interest.

Open Access This article is licensed under a Creative Commons Attribution 4.0 International License, which permits use, sharing, adaptation, distribution and reproduction in any medium or format, as long as you give appropriate credit to the original author(s) and the source, provide a link to the Creative Commons licence, and indicate if changes were made. The images or other third party material in this article are included in the article's Creative Commons licence, unless indicated otherwise in a credit line to the material. If material is not included in the article's Creative Commons licence and your intended use is not permitted by statutory regulation or exceeds the permitted use, you will need to obtain permission directly from the copyright holder. To view a copy of this licence, visit http://creativecommons.org/licenses/by/4.0/. 


\section{References}

Bailey SJ, Vanhatalo A, Wilkerson DP, Dimenna FJ, Jones AM (2009) Optimizing the "priming" effect: influence of prior exercise intensity and recovery duration on $\mathrm{O} 2$ uptake kinetics and severe-intensity exercise tolerance. J Appl Physiol 107:1743-1756

Bangsbo J, Graham T, Johansen L, Saltin B (1994) Muscle lactate metabolism in recovery from intense exhaustive exercise: impact of light exercise. J Appl Physiol 77(4):1890-1895

Bangsbo J, Krustrup P, González-Alonso J, Saltin B (2001) ATP production and efficiency of human skeletal muscle during intense exercise: effect of previous exercise. Am J Physiol Endocrinol Metab 280:E956-E964

Beaver WL, Wasserman K, Whipp BJ (1986) A new method for detecting anaerobic threshold by gas exchange. J Appl Physiol (1985) 60(6):2020-2027

Boone J, Bouckaert J, Barstow TJ, Bourgois J (2012) Influence of priming exercise on muscle deoxy $[\mathrm{Hb}+\mathrm{Mb}]$ during ramp cycle exercise. Eur J Appl Physiol 112:1143-1152

Boone J, Bourgois J (2012) The oxygen uptake response to incremental ramp exercise: methodogical and physiological issues. Sports Med 42:511-526

Børsheim E, Bahr R (2003) Effect of exercise intensity, duration and mode on post-exercise oxygen consumption. Sports Med 33:1037-1060

Burnley M, Doust JH, Carter H, Jones AM (2000) Effects of prior exercise and recovery duration on oxygen uptake kinetics during heavy exercise in humans. Exp Physiol 86:417-425

Burnley M, Doust JH, Jones AM (2006) Time required for the restoration of normal heavy exercise $\mathrm{VO} 2$ kinetics following prior heavy exercise. J Appl Physiol 101:1320-1327

Day JR, Rossiter HB, Coats EM, Skasick A, Whipp BJ (2003) The maximally attainable $\mathrm{VO} 2$ during exercise in humans: the peak vs. maximum issue. J Appl Physiol 95:1901-1907

Doherty M, Nobbs L, Noakes TD (2003) Low frequency of the "plateau phenomenon" during maximal exercise in elite British athletes. Eur J Appl Physiol 89:619-623

Edvardsen E, Hem E, Anderssen SA (2014) End criteria for reaching maximal oxygen uptake must be strict and adjusted to sex and age: a cross-sectional study. PLoS ONE 9(1):e85276

Ferguson C, Whipp BJ, Cathcart AJ, Rossiter HB, Turner AP, Ward SA (2007) Effects of prior very-heavy intensity exercise on indices of aerobic function and high-intensity exercise tolerance. J Appl Physiol 103:812-822

Ferguson C, Rossiter HB, Whipp BJ, Cathcart AJ, Murgatroyd SR, Ward SA (2010) Effect of recovery duration from prior exhaustive exercise on the parameters of the power-duration relationship. J Appl Physiol 108:866-874

Gordon D, Hopkins S, King C, Keiller D, Barnes RJ (2011) Incidence of the plateau at $\mathrm{VO} 2 \mathrm{max}$ is dependent on the anaerobic capacity. Int J Sports Med 32:1-6

Gordon D, Schaitel K, Pennefather A, Gernigon M, Keiller D, Barnes $\mathrm{R}$ (2012) The incidence of plateau at $\mathrm{VO}_{2 \max }$ is affected by a bout of prior-priming exercise. Clin Physiol Funct Imaging 32:39-44

Grassi B, Rossiter HB, Zoladz JA (2015) Skeletal muscle fatigue and decreased efficiency: two sides of the same coin? Exerc Sport Sci Rev 43:75-83

Gürsel Y, Sonel B, Gök H, Yalçin P (2004) The peak oxygen uptake of healthy Turkish children with reference to age and sex: a pilot study. Turk J Pediatr 46:38-43

Han YS, Geiger PC, Cody MJ, Macken RL, Sieck GC (2003) ATP consumption rate per cross bridge depends on myosin heavy chain isoform. J Appl Physiol 94:2188-2196
Hawkins MN, Raven PB, Snell PG, Stray-Gundersen J, Levine BD (2007) Maximal oxygen uptake as a parametric measure of cardiorespiratory capacity. Med Sci Sports Exerc 39:103-107

Hermens HJ et al (1999) European recommendations for surface ElectroMyoGraphy: results of the SENIAM project. Roessingh Research and Development, Enschede

Howley ET, Bassett DR Jr, Welch HG (1995) Criteria for maximal oxygen uptake: review and commentary. Med Sci Sports Exerc 27:1292-1301

Jones AM, Carter H (2004) Oxygen uptake-work rate relationship during two consecutive ramp exercise tests. Int J Sports Med 25:415-420

Katch VL, Sady SS, Freedson P (1982) Biological variability in maximum aerobic power. Med Sci Sports Exerc 14:21-25

Keir DA, Murias JM, Paterson DH, Kowalchuk JM (2014) Breathby-breath pulmonary $\mathrm{O} 2$ uptake kinetics: effect of data processing on confidence in estimating model parameters. Exp Physiol 99:1511-1522

Knaier R, Infanger D, Niemeyer M, Cajochen C, Schmidt-Trucksäss A (2019a) In athletes, the diurnal variations in maximum oxygen uptake are more than twice as large as the day-to-day variations. Front Physiol 18(10):219

Knaier R, Niemeyer M, Wagner J, Infanger D, Hinrichs T, Klenk C, Frutig S, Cajochen C, Schmidt-Trucksäss A (2019b) Which cutoffs for secondary $\mathrm{VO}_{2 \max }$ criteria are robust to diurnal variations? Med Sci Sports Exerc 51:1006-1013

Lamarra N, Whipp BJ, Ward SA, Wasserman K (1987) Effect of interbreath fluctuations on characterizing exercise gas exchange kinetics. J Appl Physiol 62:2003-2012

Layec G, Bringard A, Le Fur Y, Vilmen C, Micallef JP, Perrey S, Cozzone PJ, Bendahan D (2009) Effects of a prior high-intensity knee-extension exercise on muscle recruitment and energy cost: a combined local and global investigation in humans. Exp Physiol 94:704-719

Levine BD (2010) $\mathrm{VO}_{2 \max }$ : what do we know, and what do we still need to know? J Physiol 586:25-34

Lucía A, Rabadán M, Hoyos J, Hernández-Capilla M, Pérez M, San Juan AF, Earnest CP, Chicharro JL (2006) Frequency of the VO2max plateau phenomenon in world-class cyclists. Int J Sports Med 27:984-992

Mirka GA (1991) The quantification of EMG normalization error. Ergonomics 34:343-352

Marles A, Mucci P, Legrand R, Betbeder D, Prieur F (2006) Effect of prior exercise on the $\mathrm{VO} 2$ /work rate relationship during incremental exercise and constant work rate exercise. Int J Sports Med 27:345-350

Marsh CE (2019) Validity of oxygen uptake cut-off criteria in plateau identification during horizontal treadmill running. J Sports Med Phys Fitness 59:10-16

Niemeyer M, Leithaeuser R, Beneke R (2019) Oxygen uptake plateau occurrence depends on oxygen kinetics and oxygen deficit accumulation. Scand J Med Sci Sports 29:1466-1472

Niemeyer M, Bergmann TGJ, Beneke R (2020) Oxygen uptake plateau: calculation artifact or physiological reality? Eur J Appl Physiol 120:231-242

Peyer K, Pivarnik JM, Coe DP (2011) The relationship among HRpeak, RERpeak, and VO2peak during treadmill testing in girls. Res Q Exerc Sport 82:685-692

Pouilly JP, Busso T (2008) Accumulated oxygen deficit during ramp exercise. Int J Sports Med 29:16-20

Poole DC, Jones AM (2017) Measurement of the maximum oxygen uptake $\mathrm{VO}_{2 \max }: \mathrm{VO}_{2 \text { peak }}$ is no longer acceptable. J Appl Physiol 122:997-1002

Raymer GH, Forbes SC, Kowalchuk JM, Thompson RT, Marsh GD (2007) Prior exercise delays the onset of acidosis during incremental exercise. J Appl Physiol 102:1799-1805 
Sedgeman D, Dalleck L, Clark IE, Jamnick N, Pettitt RW (2013) Analysis of square-wave bouts to verify VO2max. Int J Sports Med 34:1058-1062

Shephard RJ (2009) Is it time to retire the 'central governor'? Sports Med 39:709-721

Wagner PD (2000) New ideas on limitations to $\mathrm{VO}_{2 \max }$. Exerc Sport Sci Rev 28:10-14

Wilcox SL, Broxterman RM, Barstow TJ (2016) Constructing quasilinear VO2 responses from nonlinear parameters. J Appl Physiol 120:121-129

Wittekind A, Beneke R (2011) Metabolic and performance effects of warm-up intensity on sprint cycling. Scand J Med Sci Sports $21: 201-207$
Wittekind A, Cooper CE, Elwell CE, Leung TS, Beneke R (2012) Warm-up effects on muscle oxygenation, metabolism and sprint cycling performance. Eur J Appl Physiol 112:3129-3139

Wood RE, Hills AP, Hunter GR, King NA, Byrne NM (2010) $\mathrm{VO}_{2 \max }$ in overweight and obese adults: do they meet the threshold criteria? Med Sci Sports Exerc 42:470-477

Publisher's Note Springer Nature remains neutral with regard to jurisdictional claims in published maps and institutional affiliations. 